\title{
Using nanocomposite materials technology to understand and control reverse osmosis membrane compaction
}

\author{
Mary Theresa M. Pendergast, Jodie M. Nygaard ${ }^{1}$, Asim K. Ghosh ${ }^{2}$, Eric M.V. Hoek ${ }^{*}$ \\ Department Civil and Environmental Engineering and California NanoSystems Institute, University of California, Los Angeles, CA, USA
}

\section{A R T I C L E I N F O}

Available online $\mathrm{xxxx}$

\section{Keywords:}

Reverse osmosis

Desalination

Compaction

Interfacial polymerization

Phase inversion

Nanocomposite

\begin{abstract}
A B S T R A C T
Composite reverse osmosis (RO) membranes were formed by interfacial polymerization of polyamide thin films over pure polysulfone and nanocomposite-polysulfone support membranes. Nanocomposite support membranes were formed from amorphous non-porous silica and crystalline microporous zeolite nanoparticles. For each hand-cast membrane, water flux and $\mathrm{NaCl}$ rejection were monitored over time at two different applied pressures. Nanocomposite-polysulfone supported RO membranes generally had higher initial permeability and experienced less flux decline due to compaction than pure polysulfone supported membranes. In addition, observed salt rejection tended to increase as flux declined from compaction. Crosssectional SEM images verified significant reduction in thickness of pure polysulfone supports, whereas nanocomposites better resisted compaction due to enhanced mechanical stability imparted by the nanoparticles. A conceptual model was proposed to explain the mechanistic relationship between support membrane compaction and observed changes in water flux and salt rejection. As the support membrane compacts, skin layer pore constriction increased the effective path length for diffusion through the composite membranes, which reduced both water and salt permeability identically. However, experimental salt permeability tended to decline to a greater extent than water permeability; hence, the observed changes in flux and rejection might also be related to structural changes in the polyamide thin film.
\end{abstract}

(c) 2010 Elsevier B.V. All rights reserved.

\section{Introduction}

A plethora of research since the invention of the asymmetric cellulose acetate reverse osmosis (RO) membrane in the 1950s by Loeb and co-workers has enabled production of vastly improved membrane materials with excellent water permeability and solute selectivity in addition to chemical, mechanical, and biological stability [1]. Thanks to better performing materials and numerous process engineering advances, such as high efficiency pumps and energy recovery devices, the economics of RO membrane processes have improved dramatically; RO membranes are now one of the most important and popular technologies for environmental separations, such as brackish and ocean water desalination, wastewater reclamation, and ultrapure water production [2]. However, improved membrane materials are still required to make RO membranes last longer and function more effectively in these challenging applications.

* Corresponding author. University of California, Los Angeles, 5732-G Boelter Hall, P.O. Box 951593, Los Angeles, CA 90095-1593, USA. Tel.: + 1310206 3735; fax: + 1310 2062222.

E-mail address: emvhoek@ucla.edu (E.M.V. Hoek)

1 Current address: Sanitation Districts of Los Angeles County, 1955 Workman Mill Rd., Whittier, CA 90601, USA.

${ }^{2}$ Current address: Desalination Division, Bhabha Atomic Research Centre, Trombay, Mumbai 400 085, India.
Classically, there has been a tremendous interest in membranes that are chlorine tolerant to simplify biofouling control [3], membranes that resist physical compaction [4], and membranes that resist surface fouling and that are easy to clean [5]. High applied pressures are intrinsic to RO membrane processes and external surface fouling further increases the required feed pressure. High feed pressures damage polymeric membranes internally due to physical compaction of the porous support membrane [6-9]. Subjecting a polymeric membrane to high operating pressures reorganizes the membrane macrovoid structure and results in reduced void volume and increased hydraulic resistance [10]. Irreversible, internal fouling by physical compaction remains a serious concern for RO membranes. While surface deposits are easily removed by chemical cleaning, membrane compaction is irreversible; hence, the internal, irreversible fouling of RO membranes is an important cause of higher long-term operating costs.

In a recent RO wastewater reclamation pilot study, the RO system experienced a rapid initial increase in pressure (from 9 to 11 bar in the first 2 days) followed by a gradual linear pressure increase (11 to 15 bar over the next 3 months) [4,11]. Rigorous modeling and membrane autopsy analyses suggest that the rapid initial pressure rise was predominantly associated with physical compaction, while the gradual pressure increase was mostly due to accumulation of organic matter and bacteria cells on the membrane surface. While the surface fouling was largely reversible by chemical cleaning, the loss of 
permeability due to compaction was irreversible and further exacerbated by surface fouling because of the continuously increasing applied pressure - creating a viscous feedback cycle that increased energy demand and shortens membrane useful life over time.

In another study, physical compaction of two commercially produced polyamide thin film composite membranes - a high flux RO membrane and a nanofiltration (NF) membrane - was evaluated by filtering foulant free salt solutions through the membranes [12]. Although both membranes experienced declines in their initial water and salt permeabilities, the effects of compaction were much more pronounced for the NF membrane. Electron microscopy revealed morphological differences in the RO and NF porous support membranes, which could explain the differential effects of compaction that were observed. However, it is not clear to what extent the thin film chemistry might also contribute to compaction. Typically, RO membranes comprise fully aromatic polyamide structures, whereas $\mathrm{NF}$ membranes are made from partially aromatic structures [13,14].

In other prior studies, compaction was observed in both the dense upper layer and the underlying porous support layer for asymmetric hydrogel structures $[15,16]$. The stress distribution within the membrane at a given pressure determines the way in which compaction proceeds [15]. A highly porous material is subject to a larger stress distribution than a less porous material; therefore, compaction will preferentially occur in the porous support layer of a membrane [17]. Because pores are the least mechanically stable regions of a membrane, it is the macrovoid walls that respond greatest to applied pressures $[17,18]$. As pressure is applied, pore walls become denser and macrovoids become smaller, resulting in increased tortuosity and decreased flux across the membrane $[10,19,20]$. The flux reaches a steady value when the support membrane has compacted to the point at which it resists the given pressure.

Generally, the performance and mechanical properties of a membrane are dictated by the choice of polymer, solvent, and nonsolvent. During phase inversion, solvent and nonsolvent diffuse relative to each other as the polymer solidifies to form the porous support. Macrovoid formation is a function of the relative miscibility of the solvent and nonsolvent in the casting solution. The higher the miscibility between solvent and nonsolvent, the more rapidly diffusion will occur and the more extensive pore growth will be before solidification [21-24]. Therefore, highly miscible solvent and nonsolvent may result in a porous supports with large macrovoids and a higher tendency to compact at high pressure. Polymer characteristics also play a role in macrovoid formation. For instance, the use of a highly polar and hydrophilic polymer results in large, finger-like macrovoids [25]. Polymeric additives also play a role in support layer morphology [26-28]. High molecular weight additives produce membranes with fewer macrovoids [29,30].

In mixed-matrix materials developed for other applications, inorganic particles have been used as fillers to improve properties such as stiffness, toughness, chemical stability, electrical conductivity, and resistance [31]. Typically, micrometer-sized inorganic and carbonaceous fillers are used requiring concentrations as high as $20 \%$ by volume to be effective, which often limits their application due to the high cost of the filler materials [32]. Nanocomposites comprise a unique sub-class of mixed-matrix materials where the inorganic filler is a nanoparticle. Polymer-nanocomposites have begun to attract wide interest due to improved material properties, such as increased strength and modulus, at much lower loadings than micron-sized fillers [33]. The improved properties result from favorable interfacial interactions between the nanoparticles and the polymer [32].

The use of nanoparticles based on materials such as clays, zeolites, carbon nanotubes, metals, and metal oxides have already been explored in polymeric membranes the application to thin film composite membranes for desalination is an emerging area of research [34-38]. Because of the enhanced mechanical stability observed for nanocomposite materials, RO membranes comprising polyamide thin films coated over nanocomposite-polysulfone supports were hypothesized to "resist" physical compaction better than polyamide thin films formed over pure polysulfone supports. Herein, we assess the compaction behavior of hand-cast nanocompositesupported polyamide composite membranes relative to polysulfonesupported polyamide composite membranes to help understand and control irreversible, internal fouling of RO membranes by physical compaction.

\section{Materials and methods}

\subsection{Membrane formation}

Support membrane preparation began with addition of N-methyl pyrrolidone (NMP) (Acros Organics, Morris Plains, New Jersey, USA) to a mass of transparent polysulfone beads $\left(M_{n}-26,000\right.$ from Aldrich, St. Louis, Missouri, USA) in airtight glass bottles. For nanocomposite membranes, nanoparticles were dispersed in the NMP before addition to the polysulfone beads. The solution was then agitated for several hours until complete dissolution was achieved. This prepared casting solution was spread via knife-edge over a polyester non-woven fabric ( $\mathrm{NanoH}_{2} \mathrm{O}$ Inc., Los Angeles, California, USA) previously taped to a glass plate. After spreading the casting solution, the glass plate was immediately immersed in a bath of $18 \mu \Omega$ laboratory deionized water maintained at $20 \pm 2{ }^{\circ} \mathrm{C}$. After several minutes, the non-woven support fabric with polysulfone membrane was separated from the glass plate. The membrane was then washed thoroughly with deionized water and stored in a refrigerator at $5{ }^{\circ} \mathrm{C}$.

Polyamide thin films were formed atop polysulfone and polysulfone-nanocomposite supports following previously described methods [39]. The support membrane was immersed in a $2.0 \mathrm{wt} . \%$ aqueous solution of $m$-phenylenediamine (1,3-diaminobenzene, Sigma-Aldrich, Milwaukee, Wisconsin, USA) for $15 \mathrm{~s}$. The excess MPD solution was then removed from the skin surface of the support membrane via an air knife. The membrane was then immersed into a solution of $0.1 \mathrm{wt}$ \% trimesoyl chloride (1,3,5-tricarbonyl chloride, Sigma-Aldrich, Milwaukee, Wisconsin, USA) in a proprietary isoparrafin (ExxonMobil Isopar G, Gallade Chemical, Inc., Santa Ana, California) for $15 \mathrm{~s}$ initiating polymerization. The resulting composite membranes were heat cured for $10 \mathrm{~min}$ at $82^{\circ} \mathrm{C}$, washed thoroughly with deionized water, and stored in deionized water until performance testing.

\subsection{Nanoparticle and membrane characterization}

Four of the nanocomposite membranes included non-porous, amorphous silica nanoparticles, ST50, ST20L, STZL, and MP1040 (Nissan Chemical Co, Houston, Texas, USA). Two of the nanocomposite membranes contained Linde type A (LTA) zeolite nanocrystals ( $\mathrm{NanoH}_{2} \mathrm{O}$ Inc., Los Angeles, California, USA). The LTA zeolite crystals have a three-dimensional inter-connected microporous framework providing a porous structure that enables molecular sieving. One of the zeolites used in our membranes, OMLTA, possessed a proprietary surface coating to enhance dispersion in organic solvents.

Size and zeta potential of these particles were measured in triplicate by dynamic light scattering and particle electrophoresis, respectively (Zeta PALS, Brookhaven Instrument Corp., New York, New York, USA). Before either measurement, particles were dispersed in a $10 \mathrm{mM} \mathrm{NaCl}$ solution at unadjusted $\mathrm{pH} 5.8 \pm 0.2$. Support membrane thickness and cross-sectional morphology were determined by SEM (XL30 FEG SEM, FEI Company, Hitachi, Japan). Membranes stored in DI water at $4{ }^{\circ} \mathrm{C}$ were dried overnight in a laboratory dessicator, sputter coated with gold, and immersed in liquid nitrogen to freeze fracture them for SEM imaging [40]. 


\subsection{Laboratory scale crossflow membrane system}

Hand-cast membranes were tested in a custom-built crossflow membrane filtration system designed to simultaneously test two membranes in parallel. Two identical crossflow membrane modules were constructed with dimensions of $76.2,25.4$, and $3.0 \mathrm{~mm}$ for the channel length, width, and height, respectively. The applied pressure was held constant and monitored by a back pressure regulator (Swagelok KCB, UK) and pressure gauge (Ashcroft Duralife 01000 psig, USA), while the crossflow rate was set using a bypass valve monitored with a floating disc rotameter (King Instrument Company, USA). Permeate flow rate was monitored in real-time by a digital flow meter (Agilent Optiflow 1000, USA) and calibrated periodically by measuring permeate volume over two minute intervals. A recirculating chiller (Thermo Scientific Neslab RTE-211, USA) was employed to maintain constant temperature in the feed tank by immersing a $20 \mathrm{ft}$ line of $0.25 \mathrm{in}$. steel tube coiled to fit the internal circumference of the $20 \mathrm{~L}$ polyethylene feed tank.

\subsection{Compaction experiments}

Membrane samples were placed into the crossflow membrane modules and compacted with a $10 \mathrm{mM} \mathrm{NaCl}$ feed solution at pressures of 1700 and $3400 \mathrm{kPa}$ (250 and $500 \mathrm{psi}$ ). The compaction tests continued until a steady-state flux was obtained for both membranes (typically, 16-20 h), at which point the membranes were removed and stored in a desiccator for subsequent characterization. Observed permeate water flow rate was recorded every $30 \mathrm{~min}$. Water flux was determined from

$J_{w}=\frac{Q_{p}}{A_{m}}$

where $Q_{p}$ is the permeate water flow rate and $A_{m}$ is the effective membrane area $\left(0.00194 \mathrm{~m}^{2}\right)$. Conductivity, $\mathrm{pH}$, color, and turbidity measurements of the feed and permeate streams were taken at the beginning and end of each experiment to determine salt rejection and to ensure the feedwater composition was constant and foulant free. Feed and permeate were used to calculate the observed salt rejection from

$X_{s}=1-\frac{K_{f}}{K_{p}}$,

where $K_{f}$ and $K_{p}$ were the feed and permeate conductivity.

\subsection{Estimating membrane transport coefficients}

Transport through RO membranes is generally considered to occur by a solution-diffusion type mechanism where water, $J_{w}$, and salt, $J_{s}$, flux are described by

$J_{w}=P_{w}(\Delta p-\Delta \pi)$,

$J_{s}=P_{s} \Delta c$.

Here, $\delta p$ is the (applied) trans-membrane hydraulic pressure, $\delta \delta$ is the trans-membrane osmotic pressure, while $P_{w}$ and $P_{s}$ are the apparent water and solute permeability coefficients. Trans-membrane osmotic pressure for $\mathrm{NaCl}$ can be determined from

$\Delta \pi=2 R T \Delta c$

where $R$ is the universal gas constant, $T$ is the temperature, and $\Delta c\left(=c_{m}-c_{p} ; c_{m}\right.$ is the feed-side membrane surface salt concentration; $c_{p}$ is the permeate salt concentration) is the trans-membrane solute concentration. The membrane surface salt concentration is calculated by

$\frac{c_{m}}{c_{f}}=1-X_{s}+X_{s} \exp \left(\frac{J_{w}}{k_{s}}\right)$

where $c_{f}$ is the feed concentration, $X_{s}\left(=1-c_{p} / c_{f}\right)$ is the observed salt rejection, and $k_{s}$ is the salt mass transfer coefficient. In a laboratory scale crossflow membrane filtration system without a feed spacer, the channel average mass transfer coefficient is calculated from,

$k_{s}=1.85(\operatorname{ReSc})^{1 / 3} \frac{D}{d_{h}}$.

Here, Re is the Reynolds number, Sc is the Schmidt number, $D$ is the solute diffusivity, and $d_{h}$ is the hydraulic diameter of the crossflow channel (estimated as twice the channel height) [41]. Next, the real membrane salt rejection can be calculated directly from

$R_{s}\left(=\frac{c_{m}-c_{p}}{c_{m}}\right)=1-\frac{1-X_{s}}{1-X_{s}+X_{s} \exp \left(J_{w} / k_{s}\right)}$.

Combining the measured flux and rejection with the calculated mass transfer coefficient one can estimate the pure water permeability coefficient from

$P_{w}=\frac{J_{w}}{\Delta p-2 R T R_{s} c_{m}}$,

which is obtained by combining Eq. (3) with Eqs. (5)-(8). Finally, the salt permeability coefficient can be calculated from

$P_{s}=\left(\frac{1-R_{s}}{R_{s}}\right) J_{w}$,

which is derived by substituting $J_{S}=J_{w} c_{p}$ into Eq. (4), dividing both sides by $c_{m}$, and then using the parenthetical expression from Eq. (7) to eliminate concentration terms.

\section{Results and discussion}

\subsection{Nanoparticle and membrane properties}

Physical-chemical properties of the nanoparticles and polyamide composite membranes are presented in Table 1. The silica particles ranged in size from approximately 34 to $130 \mathrm{~nm}$. The zeolite particles were much larger, ranging from approximately 250 to $300 \mathrm{~nm}$. The zeta potentials of the silica particles ranged from $-9 \mathrm{mV}$ to $-27 \mathrm{mV}$, while both zeolite particles had similar zeta potentials of -13 and $-15 \mathrm{mV}$. All of the nanocomposite-supported polyamide composite membranes had slightly smaller water contact angles than the pure TFC membrane. The zeta potentials of nanocomposite-supported polyamide composite membranes were more negatively charged than the polysulfone-supported membrane. It is assumed that the polyamide layer completely coated the supports because we could find no evidence of exposed particles on the surface (SEMs not shown); hence, the changes in hydrophilicity and charge of the membrane surface might reflect changes in the polyamide film structures formed over nanocomposite supports.

\subsection{Changes in RO membrane flux and rejection due to compaction}

Each membrane formed for this investigation was tested under 1724 and $3400 \mathrm{kPa}$ with a feed solution of $10 \mathrm{mM} \mathrm{NaCl}$. At $1724 \mathrm{kPa}$, only the OMLTA-TFC and MP1040-TFC nanocomposite-supported membranes exhibited larger flux than the polysulfone-supported membrane (Fig. 1); however, at $3400 \mathrm{kPa}$ all nanocomposite 
Table 1

Nanoparticle and membrane properties.

\begin{tabular}{|c|c|c|c|c|c|}
\hline Nanoparticle & $\begin{array}{l}\text { Diameter } \\
(\mathrm{nm})\end{array}$ & $\begin{array}{l}\text { Zeta potential } \\
(\mathrm{mV})\end{array}$ & Membrane & $\begin{array}{l}\text { Contact angle } \\
\text { (deg) }\end{array}$ & $\begin{array}{l}\text { Zeta potential } \\
(\mathrm{mV})\end{array}$ \\
\hline & & & TFC & 71 & -8 \\
\hline ST50 & 34 & -9 & ST50-TFC & 72 & -11 \\
\hline ST20L & 69 & -26 & ST20L-TFC & 70 & -9 \\
\hline ST-ZL & 130 & -26 & STZL-TFC & 70 & -13 \\
\hline MP1040 & 120 & -27 & MP1040-TFC & 69 & -12 \\
\hline LTA & 275 & -15 & LTA-TFC & 67 & -6 \\
\hline OMLTA & 275 & -13 & OMLTA-TFC & 69 & -14 \\
\hline
\end{tabular}

membranes produced larger flux. At both 1724 and $3448 \mathrm{kPa}$, observed salt rejection increased over time (Fig. 2). The single exception to this trend was LTA-TFC at $1724 \mathrm{kPa}$. At $1724 \mathrm{kPa}$, the LTA-TFC had the highest rejection, while at $3448 \mathrm{kPa}$ ST50-TFC performed best. MP1040-TFC exhibited the lowest rejection at both low and high pressure; however, it also demonstrated the greatest increase in rejection during testing at $3448 \mathrm{kPa}$. All nanocomposites performed better, in terms of higher water permeation, than the pure polysulfone TFC membrane under applied pressures of $3448 \mathrm{kPa}$ due to the enhanced mechanical strength of the support structures imparted by the nanoparticles.

(a)

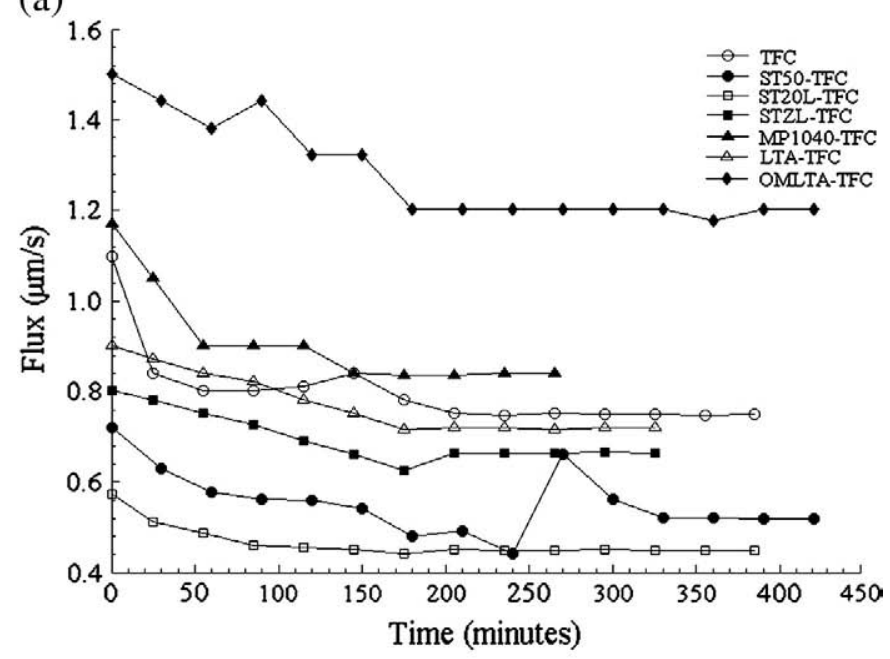

(b)

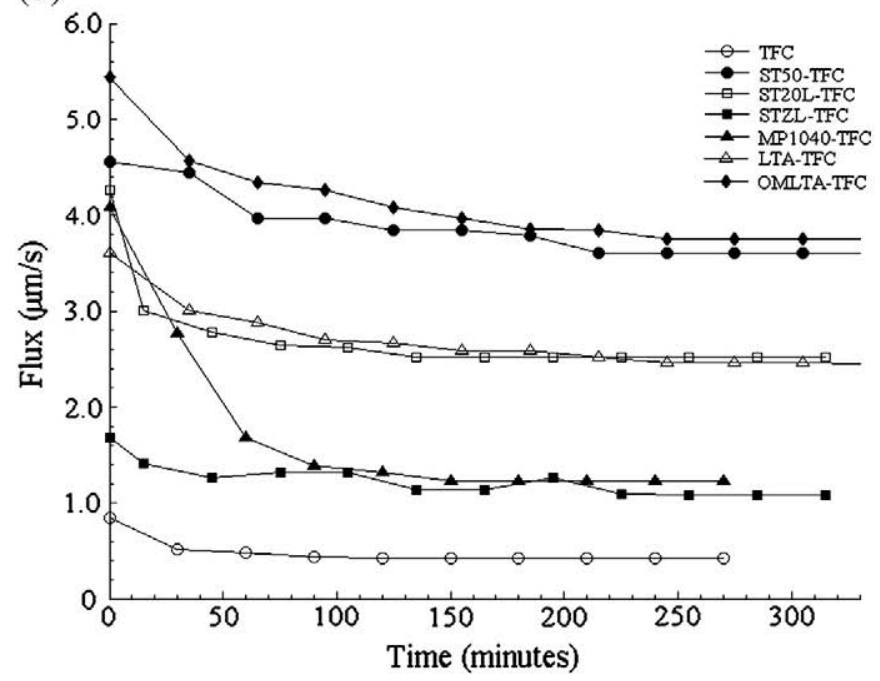

Fig. 1. Observed water flux at applied pressure of (a) 1724 and (b) $3448 \mathrm{kPa}$.

\subsection{Changes in membrane morphology due to compaction}

Cross-sectional thicknesses of uncompacted (as-cast) and compacted RO membranes were determined by analyzing SEM crosssectional images (Figs. 3-9). One image was taken on a clean section of each membrane before and after compactions. Ten thickness measurements were taken and averaged from each image. The data suggest that membranes containing nanoparticles underwent less compaction, while the pure polysulfone membrane experienced a drastic change in thickness and support structure. In general, TFN supported membranes underwent less compaction. All the

(a)

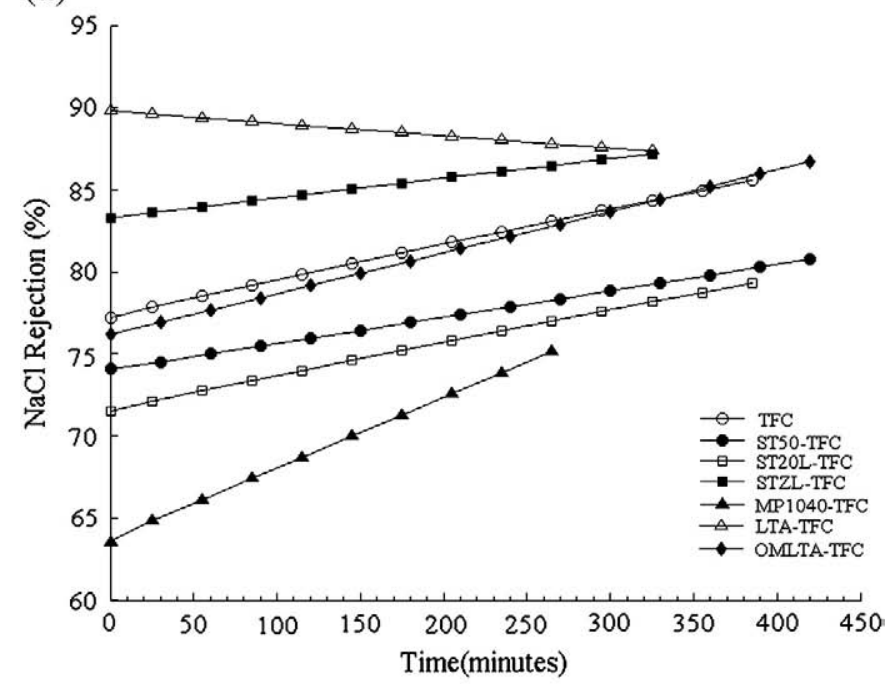

(b)

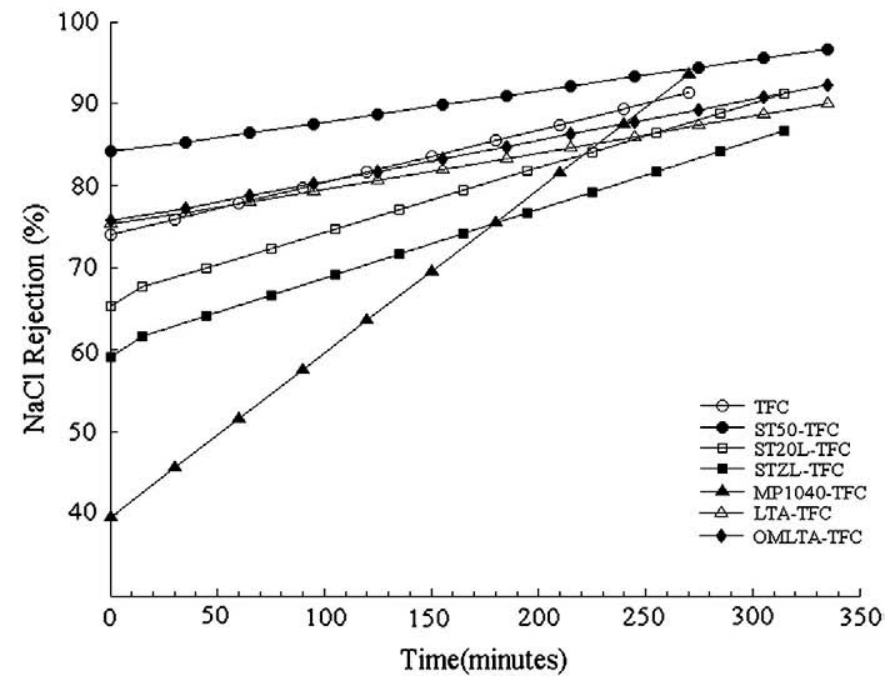

Fig. 2. Observed salt rejection at applied pressure of (a) 1724 and (b) $3448 \mathrm{kPa}$. 

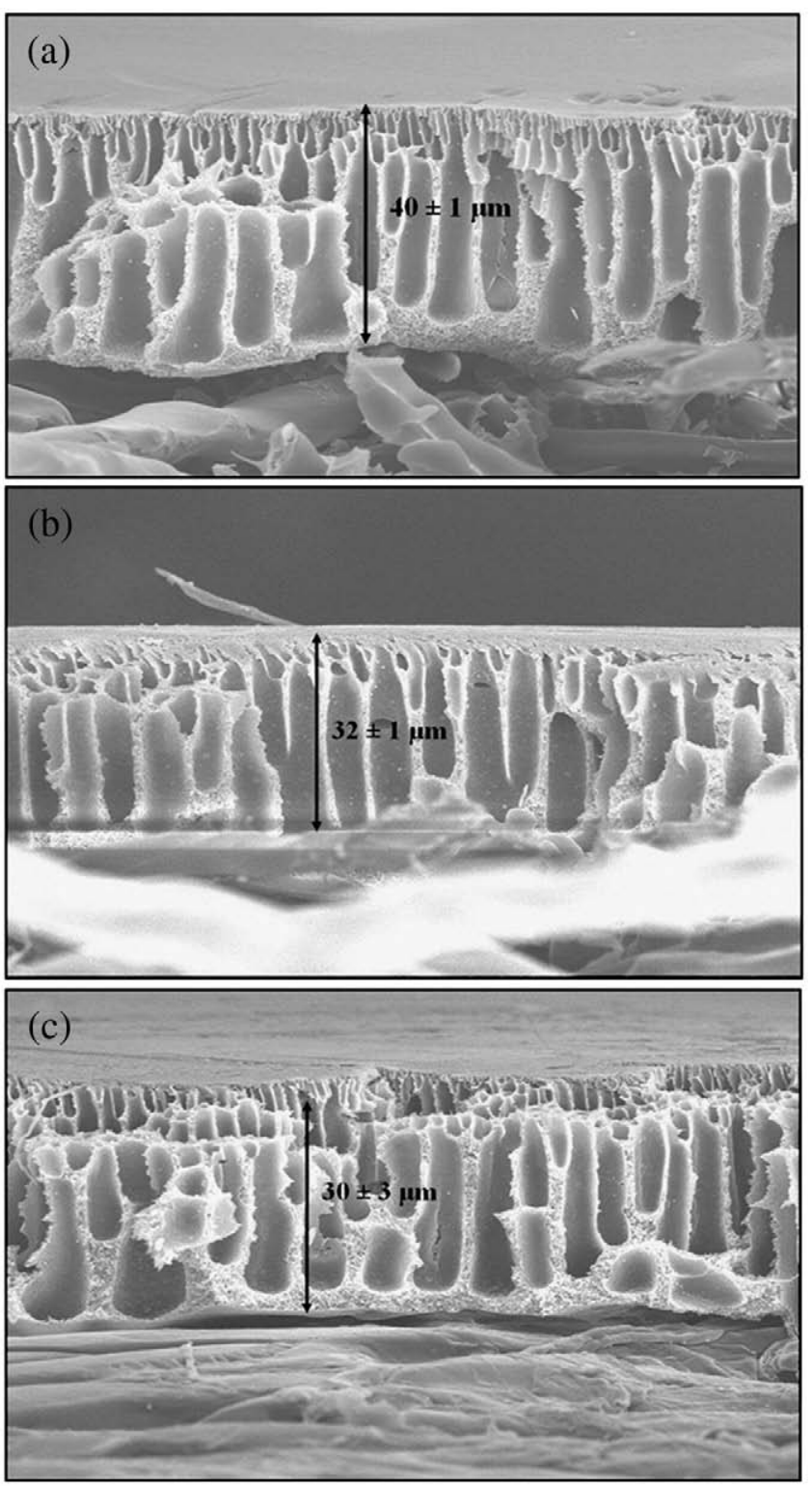

Fig. 3. SEM images of TFC (a) uncompacted and compacted at (b) 1724 and (c) $3448 \mathrm{kPa}$.

membranes containing nanoparticles appeared to maintain their uncompacted porous structure following compaction, while pure polysulfone supported membrane (TFC) macrovoid morphology changed after compaction. Hence, the addition of inorganic nanoparticles increased the mechanical stability and, therefore, decreased physical compaction of the nanocomposite supported membranes.

These results should be viewed in light of three potential sources of uncertainty in the SEM analysis. First, in our experience the thicknesses of hand-cast polysulfone membranes are quite reproducible given a fixed casting solution composition and casting blade height; however, hand-cast nanocomposite membrane thicknesses could vary quite a bit from sample-to-sample as we have much less experience with these materials. Second, the backing material on which the membranes were cast did not completely freeze-fracture; hence, membranes were torn by hand, which might have distorted the thickness determined from SEM images. Third, the exact locations of SEM images were arbitrarily chosen. Since membrane thickness could vary locally the exact cross-sectional thickness measured could be somewhat location dependent. For this reason, SEM image derived thicknesses should be considered semi-quantitative at best.
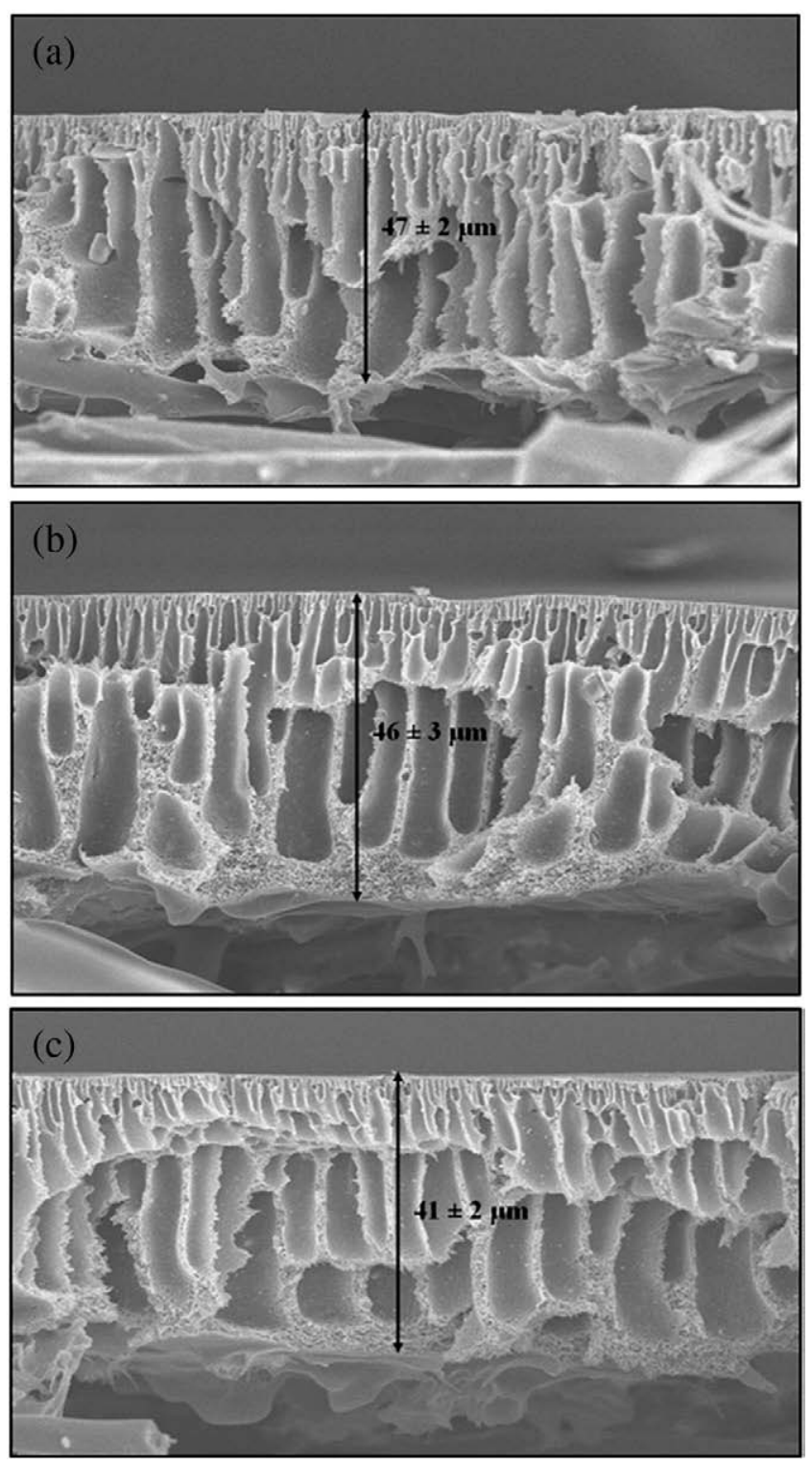

Fig. 4. SEM images of ST50-TFC (a) uncompacted and compacted at (b) 1724 and (c) $3448 \mathrm{kPa}$.

The SEM image of the uncompacted pure polysulfone TFC membrane revealed a membrane with straight through, asymmetric pores (Fig. 3). After compaction at 1724 and $3448 \mathrm{kPa}$ the membrane was visibly thinner. More importantly, the pore structure following testing at $3448 \mathrm{kPa}$ was visibly narrowed due to compaction of the support material. Surface pores were smaller and more widely spaced. ST50L-TFC membrane images showed limited structural changes following compaction (Fig. 4). The open support structure is maintained due to the nanoparticles dispersed throughout the support layer, supporting the hypothesis that the addition of nanoparticles limited the change in membrane structure caused by compaction. The virgin ST20L-TFC had a structure similar to that of TFC; however, no significant structural changes were seen following compaction at either low or high pressure (Fig. 5). The STZL-TFC membrane also maintained its structure of straight through pores after compaction (Fig. 6). Although the membrane shown following compaction at low pressure was slightly thicker than the virgin membrane, this was simply a result of local variations in imaging. Structural changes were clear in the MP1040-TFC membrane support; after compaction at $1724 \mathrm{kPa}$ the porous structure was curved and 


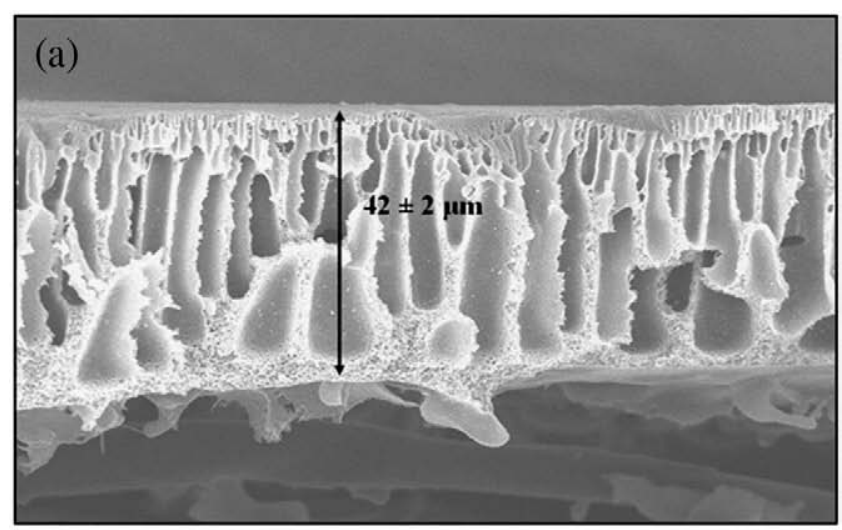

(b)

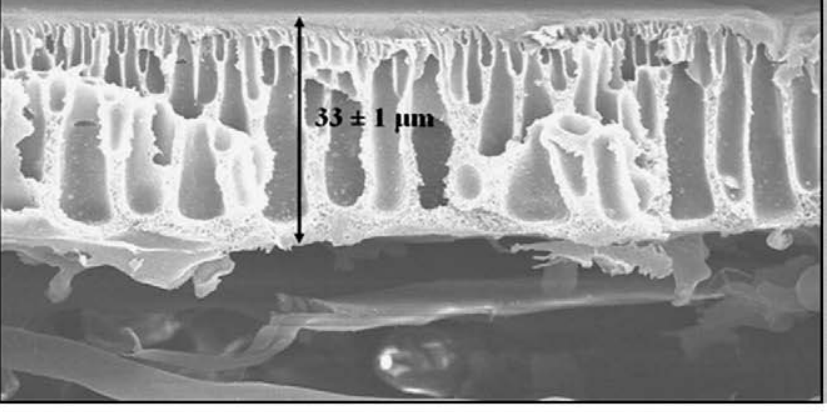

(c)

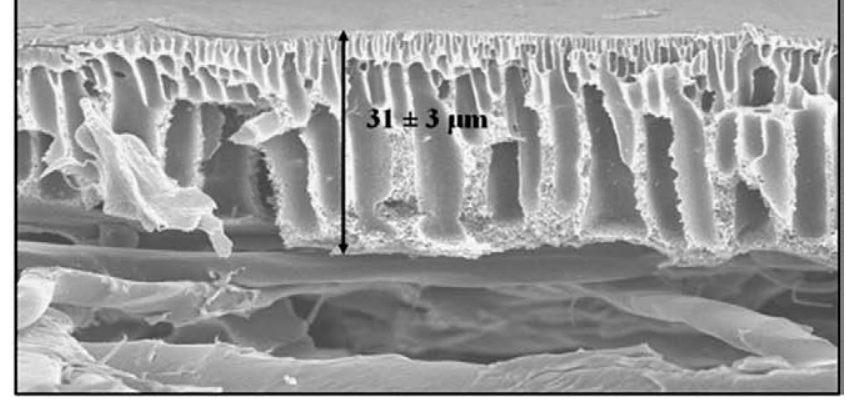

Fig. 5. SEM images of ST20L-TFC (a) uncompacted and compacted at (b) 1724 and (c) $3448 \mathrm{kPa}$.

narrowed, rather than straight-through (Fig. 7). LTA particles were visible throughout the support structure in the LTA-TFC membrane images (Fig. 8). Structural changes were limited in the LTA-TFC membrane due to the enhanced mechanical stability imparted by the well-dispersed LTA particles. The larger thickness in the membrane compacted at high pressure was, most likely, a function of the image location. Finally, SEM images of the OMLTA-TFC membranes showed that the structure was maintained after compaction at both 1724 and $3448 \mathrm{kPa}$ (Fig. 9).

SEM images reveal clustering of many of the nanoparticles within the membrane support layer. This is most clear for the MP1040 membrane following compaction at $3448 \mathrm{kPa}$, where clusters $\sim 1 \mu \mathrm{m}$ are visible (Fig. 7c). This may explain why structural changes were more apparent in MP1040-TFC than the other nanocomposite-supported membranes; when particles aggregated in the macrovoids, the porous support structure may be weakened. Rong et al. found that polymer systems with clustered nanoparticles can exhibit properties even less favorable than conventional polymer systems [32]. Therefore, steps must be taken to ensure good dispersion of nanoparticles throughout the nanocomposite during casting in order to avoid clustering.
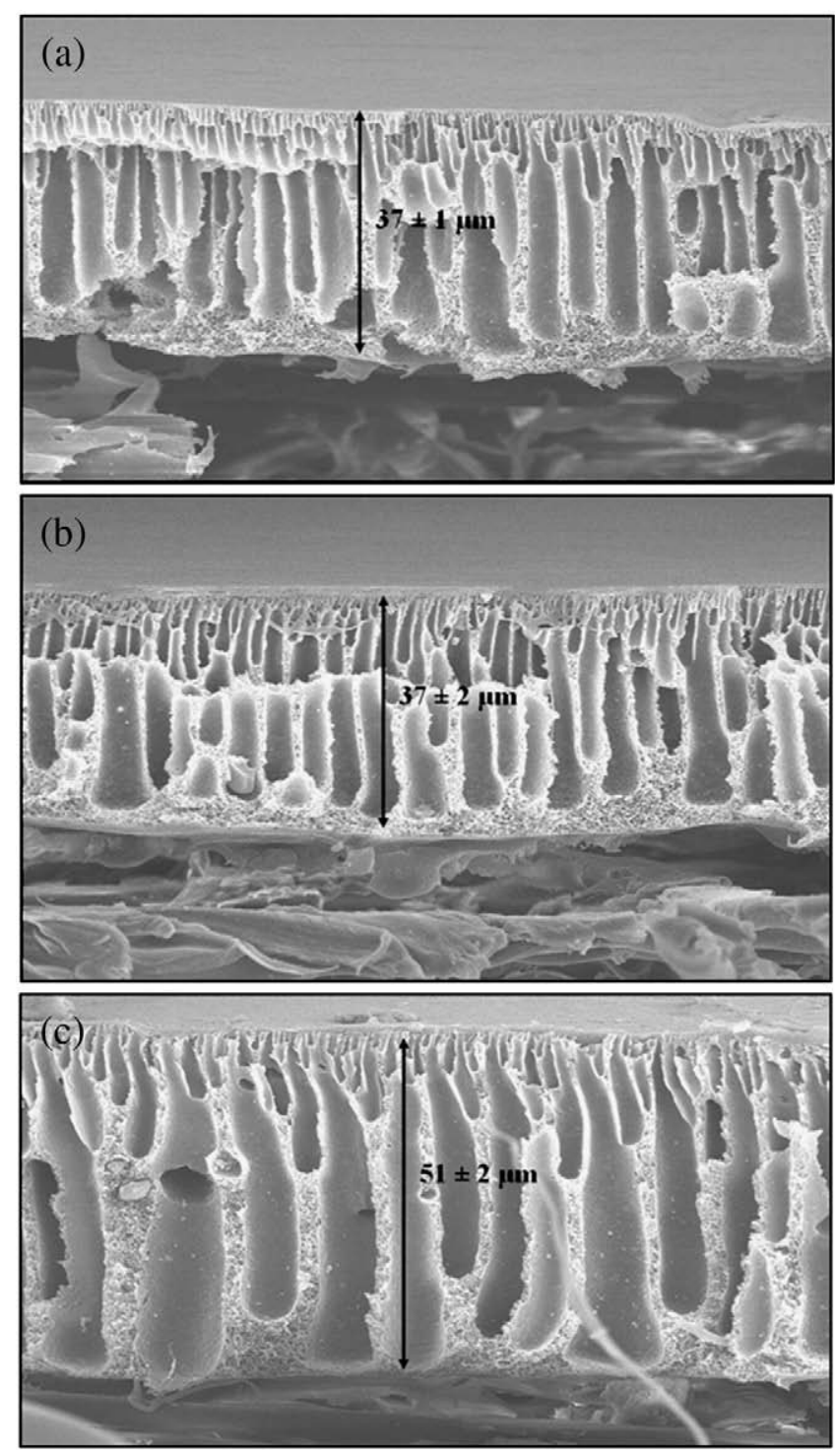

Fig. 6. SEM images of STZL-TFC (a) uncompacted and compacted at (b) 1724 and (c) $3448 \mathrm{kPa}$.

\subsection{Conceptual mechanistic model of membrane compaction}

In the experimental data presented above, as compaction progressed the observed water flux decreased while salt rejection increased. Selectivity of RO membranes is generally thought to arise from differences in solubility and diffusivity of water and salt in the polyamide thin film. Following this logic, one can define the water and solute permeability coefficients from

$P_{w}=\frac{D_{w} S_{w}}{\Delta x_{e f f}}$

$P_{s}=\frac{D_{s} S_{s}}{\Delta x_{e f f}}$

where $S_{w}$ and $S_{s}$ are the solubilities of water and salt in the membrane, $D_{w}$ and $D_{s}$ are the diffusivities of water and salt through the membrane, and $\Delta x_{\text {eff }}$ is effective path length for diffusion. It follows that the water and salt permeability should decrease if the effective path length for diffusion increases. 

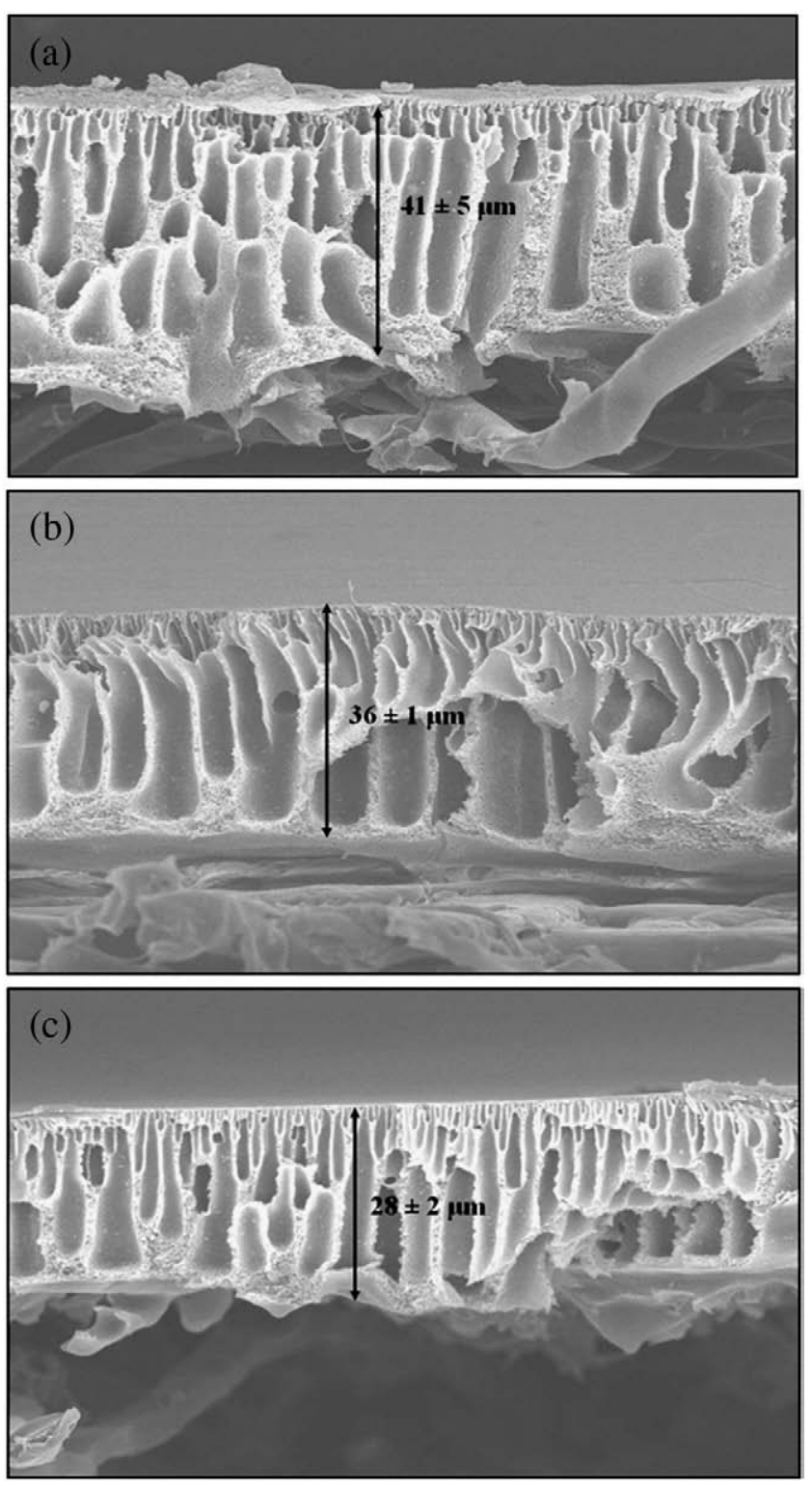

Fig. 7. SEM images of MP1040-TFC (a) uncompacted and compacted at (b) 1724 and (c) $3448 \mathrm{kPa}$.

This framework was originally proposed by Lonsdale et al. [42] to explain composite membrane performance, but was adapted herein to describe the effects of support membrane compaction on performance (Fig. 10). As a porous support membrane compacts, its surface pores become narrower because the finite mass of support membrane polymer is forced to occupy a smaller total volume of space. The support membrane surface pore radii $\left(r_{1}\right)$ become smaller, thereby increasing the effective separation distance between surface pores $\left(r_{2}\right)$, which ultimately increases the effective path length, $\Delta x_{\text {eff, }}$, for water and salt diffusion through the thin film. In Fig. 10b, the pore radius $\left(r_{1}\right)$ is smaller while the number of pores remains the same; therefore, the effective path length for water and solute diffusion through the membrane is longer and permeability (for both water and salt) declines identically.

This compaction model was put to the test by converting the observed flux and rejection data into water and solute permeability coefficients using Eqs. (3)-(10) (Table 2). The calculated permeability coefficients show that both water and salt permeability decreased due
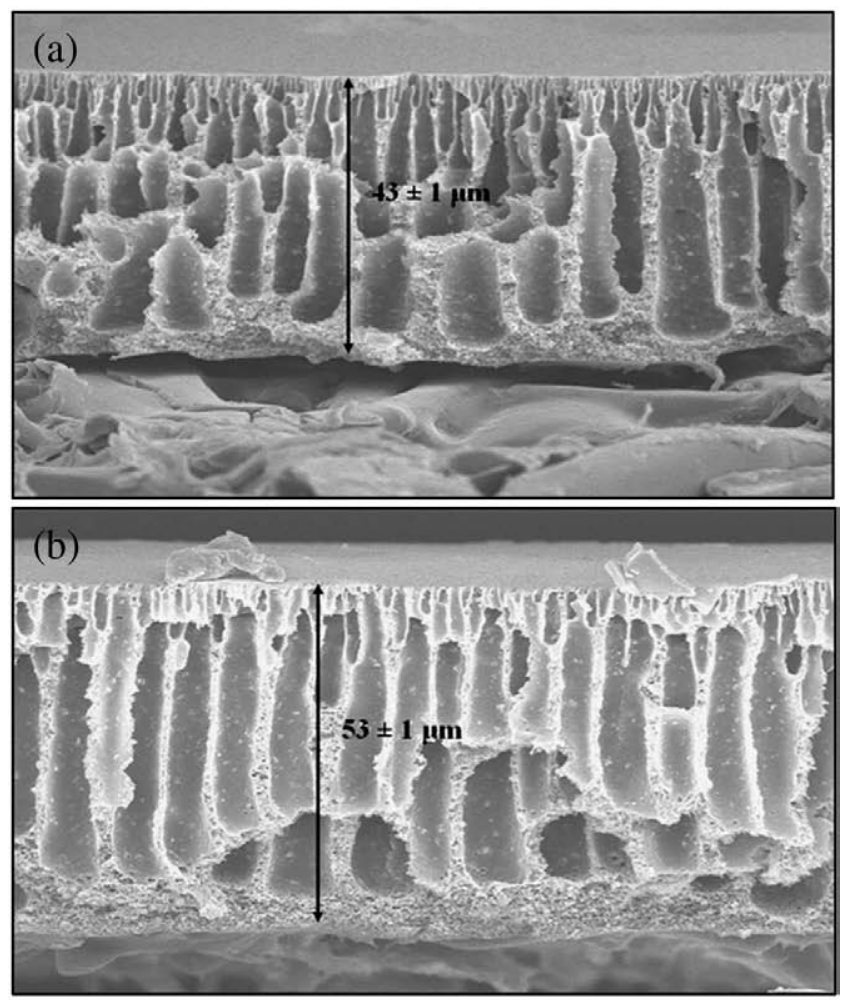

(c)

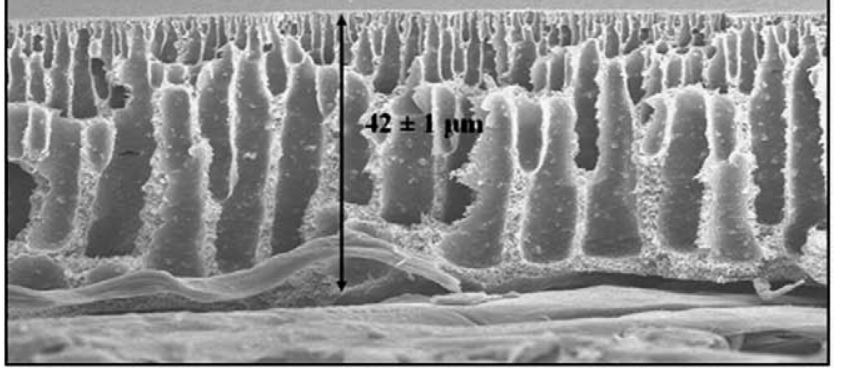

Fig. 8. SEM images of LTA-TFC (a) uncompacted and compacted at (b) 1724 and (c) $3448 \mathrm{kPa}$

to compaction. Salt permeability decreased more than water permeability, which was not expected from the compaction model proposed but could explain the finding that observed salt rejection increased even though the water flux decreased during the experiments. If the decline in salt permeability was assumed equal to the decline in water permeability, the observed salt rejection would have decreased for every membrane tested. The increase in salt rejection suggests that compaction may have also occurred in the polyamide thin film, which should not be affected by the presence of nanoparticles in the support layer and cannot be described by the proposed conceptual model. The proposed model points to the collapse of surface pores rather than macrovoids as one important mechanism through which polyamide composite RO membrane performance declines due to physical compaction. Perhaps more important, is that the proposed compaction model only partially explained experimentally observed changes in flux and rejection, which implies that further research is warranted to fully understand the causes, consequences and potential counter-measures of RO 

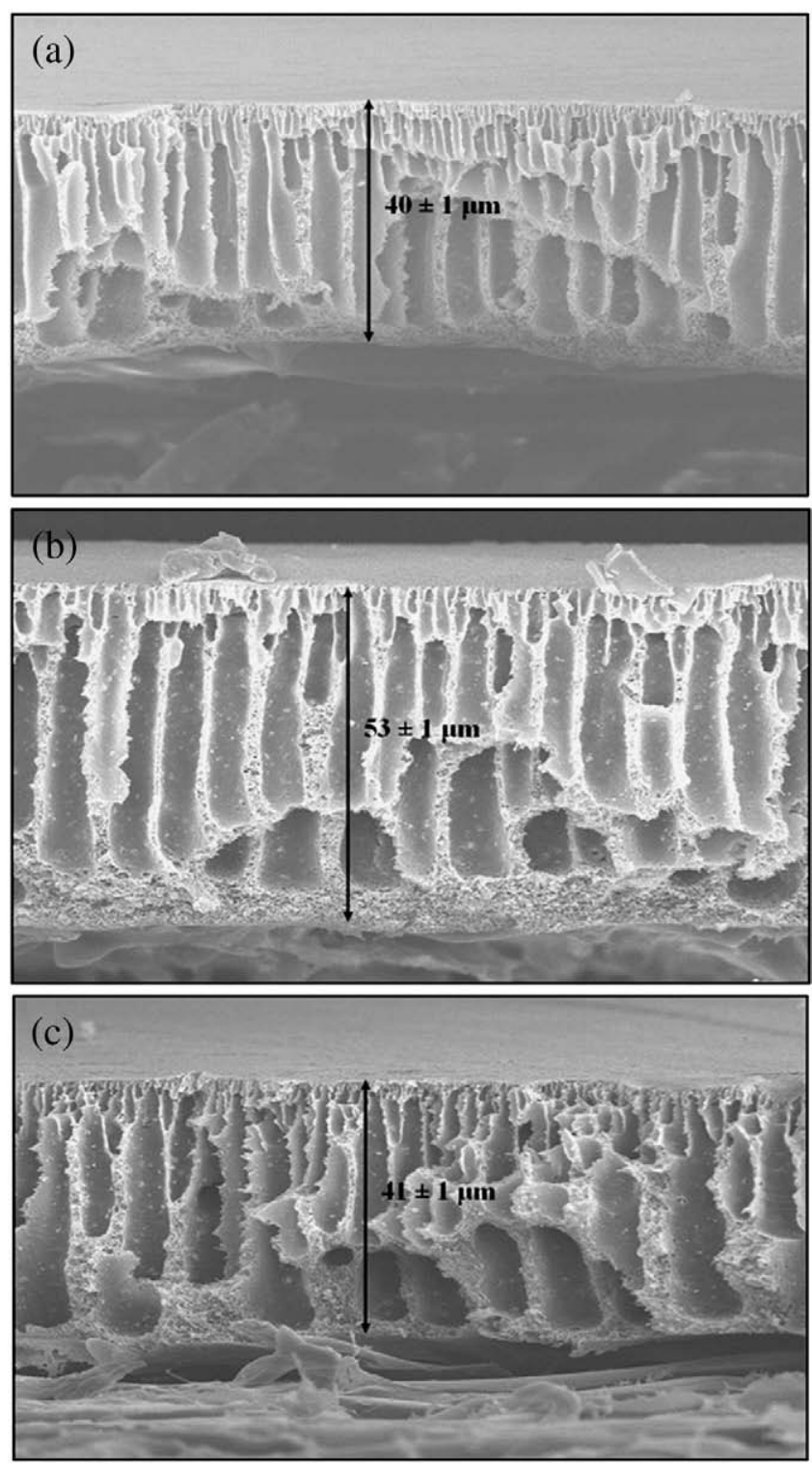

Fig. 9. SEM images of OMLTA-TFC (a) uncompacted and compacted at (b) 1724 and (c) $3448 \mathrm{kPa}$.

membrane compaction. This new understanding of composite RO membrane compaction has two practical implications.

The first implication of these results is for membrane manufacturing. In order to minimize the deleterious effects of physical compaction, mechanical properties of RO membranes must be continuously improved. Nanocomposite support membranes offer one potential means towards this end. However, the same nanoparticle produced inconsistent changes in membrane properties when exposed to different pressures. After compaction at $1724 \mathrm{kPa}$ (250 psi), all nanocomposite supported RO membranes resisted compaction better, but some were more permeable while others were less permeable than the pure polysulfone supported membranes. At $3448 \mathrm{kPa}$ (500 psi) applied pressure, all nanocomposite RO membranes were more permeable before compaction and suffered less compaction. Since surface pore collapse is the key mechanism of compaction, nanoparticles might not be needed throughout the support membrane cross-section, but only within the skin layer. More research is needed to fully understand the mechanisms of compaction within the polyamide layer, and to develop robust (a)

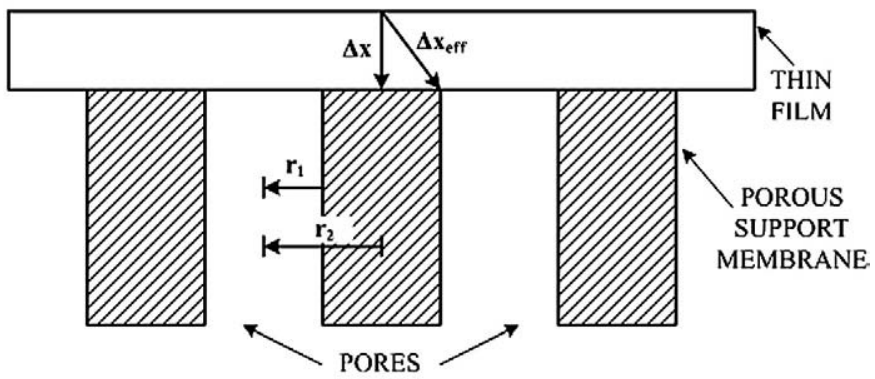

(b)

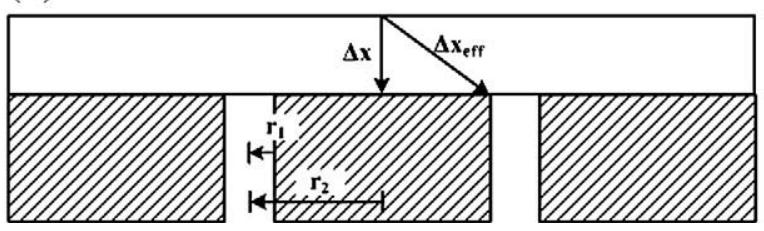

Fig. 10. Conceptual illustrations of (a) the relationship between porous support membrane pore size and spacing, i.e., porosity, and effective thin film thickness, i.e., water and solute diffusion path length and (b) change in support membrane pore morphology and effective diffusion path length after physical compaction. Images and concept adapted from [42].

methods of improving both support membrane and coating film mechanical properties.

The second implication of these results is for RO plant design and operation. Currently, as flux declines the applied pressure is increased to maintain constant permeate water production. The increase of pressure causes greater compaction and more irreversible flux decline. A better strategy may be to operate at constant pressure allowing the flux to decline, but bringing additional membrane elements online to maintain the desired plant output. Although this approach is highly inconsistent with modern operational strategies, in the future as the cost of energy increases and the cost of RO membranes decreases, it may prove more cost effective to add more membrane area as fouling progresses rather than to increase applied pressure.

\section{Conclusions}

Reverse osmosis membranes comprising polyamide thin films interfacially polymerized over polysulfone and nanocomposite-

Table 2

Changes in water and salt permeability by compaction

\begin{tabular}{|c|c|c|c|c|c|c|}
\hline \multirow{2}{*}{$\begin{array}{l}\text { Membrane } \\
\text { composition }\end{array}$} & \multicolumn{2}{|c|}{$P_{w}(\mu \mathrm{m} / \mathrm{MPa}-\mathrm{s})$} & \multirow{2}{*}{$\begin{array}{l}\Delta P_{w} \\
(\%)\end{array}$} & \multicolumn{2}{|c|}{$P_{s}(\mu \mathrm{m} / \mathrm{s})$} & \multirow{2}{*}{$\begin{array}{l}\Delta P_{s} \\
(\%)\end{array}$} \\
\hline & Start & End & & Start & End & \\
\hline \multicolumn{7}{|c|}{ (a) $1724 \mathrm{kPa}$ (250 psi) applied pressure } \\
\hline TFC & 0.652 & 0.446 & -32 & 0.32 & 0.12 & -62 \\
\hline ST50-TFC & 0.427 & 0.308 & -28 & 0.25 & 0.12 & -52 \\
\hline ST20L-TFC & 0.339 & 0.266 & -21 & 0.22 & 0.12 & -46 \\
\hline STZL-TFC & 0.467 & 0.395 & -17 & 0.16 & 0.10 & -39 \\
\hline MP1040-TFC & 0.691 & 0.498 & -28 & 0.66 & 0.27 & -59 \\
\hline LTA-TFC & 0.536 & 0.429 & -20 & 0.10 & 0.10 & 8 \\
\hline OMLTA-TFC & 0.889 & 0.714 & -20 & 0.45 & 0.17 & -62 \\
\hline \multicolumn{7}{|c|}{ (b) $3447 \mathrm{kPa}$ (500 psi) applied pressure } \\
\hline TFC & 0.245 & 0.112 & -50 & 0.50 & 0.06 & -88 \\
\hline ST50-TFC & 1.325 & 1.046 & -21 & 0.74 & 0.10 & -87 \\
\hline ST20L-TFC & 1.240 & 0.732 & -41 & 1.97 & 0.23 & -88 \\
\hline STZL-TFC & 0.488 & 0.314 & -36 & 1.10 & 0.16 & -86 \\
\hline MP1040-TFC & 1.187 & 0.357 & -70 & 5.29 & 0.09 & -98 \\
\hline LTA-TFC & 1.046 & 0.712 & -32 & 1.05 & 0.25 & -76 \\
\hline OMLTA-TFC & 1.580 & 1.093 & -31 & 1.41 & 0.29 & -80 \\
\hline
\end{tabular}


polysulfone support membranes were evaluated in an attempt to better understand and mitigate RO membrane compaction. All handcast membranes lost water and salt permeability due to compaction. All but one nanocomposite-polysulfone supported RO membrane experienced less flux decline compared to pure polysulfone supported RO membranes. The performance advantage of nanocompositesupported membranes was greater at higher applied pressure. Electron microscope images support the hypothesis that nanocomposite supports resisted physical compaction. A conceptual model originally proposed by Lonsdale et al. [42] provided a mechanistic framework to relate changes in composite membrane flux and rejection to support membrane compaction. Nanocomposite-supported RO membranes represent one potential approach to mitigate internal, irreversible fouling due to membrane compaction, particularly in high-pressure applications like brackish and ocean water desalination. However, significant research is needed to fully understand the mechanisms of membrane compaction and how to improve the design and fabrication of compaction resistant RO membranes.

\section{Disclosure}

The authors EMVH and AKG have a financial interest in one of the project co-sponsors, $\mathrm{NanoH}_{2} \mathrm{O}$ Inc., through stock ownership and consulting agreements.

\section{Acknowledgements}

This publication is based on the work supported in part by Award No. KUS-C1-018-02, made by King Abdullah University of Science and Technology (KAUST), in addition to the UCLA California NanoSystems Institute (CNSI) and $\mathrm{NanoH}_{2} \mathrm{O}$ Inc. Additional financial support for MTMP was provided by the UCLA Cota Robles Fellowship and the UCLA Faculty Women's Club Russell and Sallie O'Neill Memorial Scholarship, and for JMN by the Environmental Engineers for the Future funding program.

\section{References}

[1] S. Loeb, S. Sourirajan, Sea water demineralization by means of an osmotic membrane, Adv. Chem. Ser. 38 (1962) 117-132.

[2] M. Elimelech, M. Wiesner, Membrane separations in aquatic systems, Environ. Eng. Sci. 19 (2002) 341.

[3] J. Glater, S. Hong, M. Elimelech, The search for a chlorine-resistant reverse osmosis membrane, Desalination 95 (1994) 325-345.

[4] K. Ebert, D. Fritsch, J. Koll, C. Tjahjawiguna, Influence of inorganic fillers on the compaction behaviour of porous polymer based membranes, J. Membr. Sci. 233 (2004) 71-78.

[5] S. Belfer, Y. Purinson, R. Fainshtein, Y. Radchenko, O. Kedem, Surface modification of commercial composite polyamide reverse osmosis membranes, J. Membr. Sci. 139 (1998) 175-181.

[6] R. Mahendran, R. Malaisamy, D. Mohan, Preparation, characterization and effect of annealing on performance of cellulose acetate/sulfonated polysulfone and cellulose acetate/epoxy resin blend ultrafiltration membranes, Eur. Polym. J. 40 (2004) 623-633.

[7] M. Sivakumar, R. Malaisamy, C.J. Sajitha, D. Mohan, V. Mohan, R. Rangarajan, Ultrafiltration application of cellulose acetate-polyurethane blend membranes, Eur. Polym. J. 35 (1999) 1647-1651.

[8] N.A. Ochoa, M. Masuelli, J. Marchese, Effect of hydrophilicity on fouling of an emulsified oil wastewater with PVDF/PMMA membranes, J. Membr. Sci. 226 (2003) 203-211.

[9] V.R. Tarnawski, P. Jelen, Estimation of compaction and fouling effects during membrane processing of cottage cheese whey, J. Food Eng. 5 (1986) 75-90.

[10] K.M. Persson, V. Gekas, G. Tragardh, Study of membrane compaction and its influence on ultrafiltration water permeability, J. Membr. Sci. 100 (1995) 155-162.

[11] E.M.V. Hoek, J. Allred, T. Knoell, B.-H. Jeong, Modeling the effects of fouling on fullscale reverse osmosis processes, J. Membr. Sci. 314 (2008) 33-49.

[12] J.M. Nygaard, Combating long-term, irreversible fouling with nanocomposite membrane technology, Thesis for Degree of Master of Science, Civil and Environmental Engineering, University of California, Los Angeles, 2006.
[13] K.E. Perepelkin, Inverse evaluation of the integral ordering of the structure and defectiveness of fibres and yarns for technical applications based on normalized values of the mechanical properties, Fibre. Chem. 28 (1996) 326-335.

[14] M. Mulder, Basic Principles of Membrane Technology, 2nd EdKluwer Academic Publishers, Boston, MA, 1996.

[15] L. Baayens, S.L. Rosen, Hydrodynamic resistance and flux decline in asymmetric cellulose acetate reverse osmosis membranes, J. Appl. Polym. Sci. 16 (1972) 663-670.

[16] G. Jonsson, Methods for determining the selectivity of reverse osmosis membranes, Desalination 24 (1978) 19-37.

[17] H.Z. Ye, D.Y. Li, R.L. Eadie, Influences of porosity on mechanical and wear performance of pseudoelastic mixed-matrix composites, J. Mater. Eng. Perform. 10 (2001) 178-185.

[18] M.G. Khedr, Development of reverse osmosis desalination membranes composition and configuration: future prospects, Desalination 153 (2002) 295-304.

[19] R. Malaisamy, D.R. Mohan, M. Rajendran, Polyurethane and sulfonated polysulfone blend ultrafiltration membranes: I. Preparation and characterization studies, J. Colloid Interf. Sci. 254 (2002) 129-140.

[20] H. Lonsdale, U. Merten, R. Riley, Transport properties of cellulose acetate osmotic membranes, J. Appl. Polym. Sci. 9 (1965) 1341-1362.

[21] H. Strathmann, K. Kock, The formation mechanism of phase inversion membranes, Desalination 21 (1977) 241-255.

[22] J. Wijmans, M. Mulder, J. Kant, C. Smolders, Phase separation phenomena in solutions of polysulfone in mixtures of a solvent and a nonsolvent: relationship with membrane formation, Polymer 26 (1985) 1539.

[23] C. Smolders, A. Reuvers, R. Boom, I. Wienk, Microstructures in phase-inversion membranes, I. Formation of macrovoids, J. Membrane Sci. 73 (1992) 259-275.

[24] T.-H. Young, L.-W. Chen, Pore formation mechanism of membranes from phase inversion process, Desalination 103 (1995) 233-247.

[25] C. Barth, M.C. Goncalves, A.T.N. Pires, J. Roeder, B.A. Wolf, Asymmetric polysulfone and polyethersulfone membranes: effects of thermodynamic conditions during formation on their performance, J. Membr. Sci. 169 (2000) 287-299.

[26] T. Uragami, M. Fujimoto, M. Sugihara, Studies on syntheses and permeabilities of special polymer membranes, 28. Permeation characteristics and structure of interpolymer membranes from poly(vinylidene fluoride) and poly(styrene sulfonic acid), Desalination 34 (1980) 311-323.

[27] M. Sivakumar, R. Malaisamy, C.J. Sajitha, D. Mohan, v. Mohan, R. Rangarajan, Preparation and performance of cellulose acetate-polyurethane blend membranes and their applications-II, J. Membr. Sci. 169 (2000) 215-228.

[28] S. Prabhaker, M. BM, Studies on the structural, kinetic and thermodynamic parameters of cellulose acetate membranes, J. Membr. Sci. 29 (1986) 143-153.

[29] R.M. Boom, I.M. Wienk, T.v.d. Boomgaard, C.A. Smolders, Microstructures in phase inversion membranes: 2. The role of a polymeric additive, J. Membr. Sci. 73 (1992) 277-292.

[30] R. Kesting, Synthetic Polymeric Membranes, Wiley-Interscience, New York, NY, 1985

[31] M. Alexandre, P. Dubois, Polymer-layered silicate nanocomposites: preparation, properties and uses of a new class of materials, Mater. Sci. Eng. 28 (2000) 1-63.

[32] M.Z. Rong, M.Q. Zhang, Y.X. Zheng, H.M. Zeng, R. Walter, K. Friedrich, Structureproperty relationships of irradiation grafted nano-inorganic particle filled polypropylene composites, Polymer 42 (2001) 167-183.

[33] J.R. Fried, Polymer Science and Technology, 2nd EdPrentice Hall Professional Technical Reference, Upper Saddle River, 2003.

[34] B.H. Jeong, E.M.V. Hoek, Y. Yan, A. Subramani, X. Huang, G. Hurwitz, A. Ghosh, A. Jawor, Interfacial polymerization of thin film nanocomposites: a new concept for reverse osmosis membranes, J. Membr. Sci. 294 (2007) 1-7.

[35] M. Lind, B. Jeong, A. Subramani, X. Huang, E.M.V. Hoek, Effect of mobile cation on zeolite-polyamide thin film nanocomposite membranes, J. Mater. Res. 24 (2009) 1624-1631.

[36] S. Warren, L. Messina, L. Slaughter, M. Kamperman, Q. Zhou, S. Gruner, F. DiSalvo, U. Wiesner, Ordered mesoporous materials from metal nanoparticle-block copolymer self-assembly, Science 320 (2008) 1748.

[37] J. Taurozzi, H. Arul, V. Bosak, A. Burban, T. Voice, M. Bruening, V. Tarabara, Effect of filler incorporation route on the properties of polysulfone-silver nanocomposite membranes of different porosities, J. Membr. Sci. 325 (2008) 58-68.

[38] M. Lind, A. Ghosh, A. Jawor, X. Huang, W. Hou, Y. Yang, E.M.V. Hoek, Influence of zeolite crystal size on zeolite-polyamide thin film nanocomposite membranes, Langmuir 25 (2009) 10139-10145.

[39] A. Ghosh, B. Jeong, X. Huang, E.M.V. Hoek, Impacts of reaction and curing conditions on polyamide composite reverse osmosis membrane properties, J. Membr. Sci. 311 (2008) 34-45.

[40] O.L. Orelovitch, P.Y. Apel, B. Sartowska, Preparation of porous polymer samples for SEM: combination of photo oxidation degradation with a freeze fracture technique, Mater. Chem. Phys. 81 (2003) 349-351.

[41] E.M.V. Hoek, A. Kim, M. Elimelech, Influence of crossflow membrane filter geometry and shear rate on colloidal fouling in reverse osmosis and nanofiltration separations, Environ. Eng. Sci. 19 (2002) 357-372.

[42] H. Lonsdale, R. Riley, C. Lyons, D. Carosella Jr, Transport in composite reverse osmosis membranes, in: M. Bier (Ed.), Membrane Processes in Industry and Biomedicine, Plenum Press, New York, NY, 1971. 